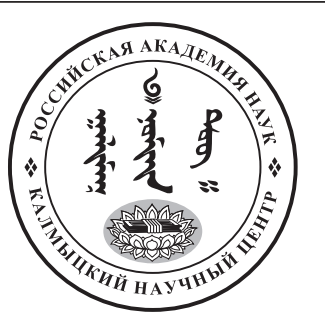

Published in the Russian Federation

Oriental Studies (Previous Name: Bulletin of the Kalmyk Institute

for Humanities of the Russian Academy of Sciences)

Has been issued as a journal since 2008

ISSN: 2619-0990; E-ISSN: 2619-1008

Vol. 14, Is. 6, pp. 1267-1280, 2021

Journal homepage: https://kigiran.elpub.ru

УДК / UDC 397.4

DOI: $10.22162 / 2619-0990-2021-58-6-1267-1280$

\title{
Хозяйственные обязанности мужчин и женщин в кочевых обществах Центральной Евразии XVIII - начала XX вв.
}

\author{
Александр Дмитриевич Таиров ${ }^{1}$, Наталья Александровна Берсенева ${ }^{2}$ \\ ${ }^{1}$ Южно-Уральский государственный университет (национальный исследовательский университет) \\ (д. 76, пр. Ленина, 454080 Челябинск, Российская Федерация) \\ доктор исторических наук, директор \\ iD 0000-0001-8575-0430.E-mail: tairov55@mail.ru \\ ${ }^{2}$ Южно-Уральский государственный университет (национальный исследовательский университет) \\ (д. 76, пр. Ленина, 454080 Челябинск, Российская Федерация) \\ доктор исторических наук, старший научный сотрудник \\ D 0000-0003-2554-6205. E-mail: bersnatasha@mail.ru \\ (C) КалмНЦ РАН, 2021 \\ (C) Таиров А. Д., Берсенева Н. А., 2021
}

\begin{abstract}
Аннотация. Введение. В ранних кочевых обществах Центральной Евразии существовало разделение труда по гендерному признаку. Однако письменные источники и данные археологии не позволяют охарактеризовать это разделение. Решение проблемы возможно, если обратиться к данным этнографии по кочевым в недавнем прошлом народам. Целью исследования является определение хозяйственных обязанностей мужчин и женщин в кочевых обществах Центральной Евразии XVIII - начала XX вв. для реконструкции гендерного разделения труда в обществах ранних кочевников исследуемого региона. Mатериаль и методы. Для характеристики разделения хозяйственных обязанностей по половому признаку использованы источники нового времени по кочевым народам. Авторы исходили из того, что специфика кочевой экономики и экологически сходные условия, которые приводят к выработке однотипных форм кочевого хозяйства, позволяют привлекать данные по кочевым в недавнем прошлом народам для реконструкции хозяйства и культуры древних номадов евразийских степей. Результаты и обсуждение. Изучение источников позволило дифференцировать хозяйственные обязанности в кочевых обществах Центральной Евразии XVIII - начала XX вв. по половому признаку и составить их список. Традиция достаточно жестко закрепляла разделение обязанностей на мужские и женские. Выполнение не свойственных полу работ вызывало негативное отношение окружающих. Bblвoдbl. В кочевых обществах Центральной Евразии нового времени был четко обозначен круг хозяйственных обязанностей мужчин и женщин. Распределение их не зависело от национальной принадлежности и господствующей в обществе религии. На мужчине лежали обязанности, выполнение которых обеспечивало сохранение и воспроизводство
\end{abstract}


стада. Мужскими были также основные ремесла. Мужчины занимались обслуживанием и охраной караванов. Мужчины обязаны были защищать семью и аул, имущество и скот от набегов противника и баранты. Женщины занимались воспитанием детей и домашними делами. Они обрабатывали животное сырье, ухаживали за скотом в ауле, заготавливали продукты и топливо на зиму. Распределение хозяйственных обязанностей между мужчинами и женщинами, зафиксированное у кочевников XVIII - начала XX вв. Центральной Евразии позволяет использовать имеющиеся данные для реконструкции гендерного разделения труда в обществах ранних кочевников евразийских степей.

Ключевые слова: башкиры, казахи, калмыки, киргизы, туркмены, кочевники, мужчина, женщина, хозяйственные обязанности

Благодарность. Исследование выполнено при финансовой поддержке РФФИ в рамках научных проектов № 20-49-740005 «Образ жизни и социальная структура ранних кочевников Южного Урала в конце VII-III вв. до н. э.» (А. Д. Таиров) и № 20-09-00205 «Культура и общество ранних кочевников Южного Зауралья (по материалам могильника Кичигино I) (Н. А. Берсенева).

Для цитирования: Таиров А. Д., Берсенева Н. А. Хозяйственные обязанности мужчин и женщин в кочевых обществах Центральной Евразии XVIII - начала XX вв. // Oriental Studies. 2021. T. 14. № 6. C.1267-1280. DOI: 10.22162/2619-0990-2021-58-6-1267-1280

\title{
Nomadic Communities of Central Eurasia, 18 $^{\text {th }}-$ Early $2^{\text {th }}$ Centuries CE: Household and Economic Responsibilities of Men and Women Revisited
}

\author{
Alexandr D. Tairov ${ }^{1}$, Natalia A. Berseneva ${ }^{2}$ \\ ${ }^{1}$ South Ural State University (76, Lenin Ave., 454080 Chelyabinsk, Russian Federation) \\ Dr. Sc. (History), Director of Center for Eurasian Studies \\ iD 0000-0001-8575-0430. E-mail: tairov55@mail.ru \\ ${ }^{2}$ South Ural State University (76, Lenin Ave., 454080 Chelyabinsk, Russian Federation) \\ Dr. Sc. (History), Senior Research Associate \\ 0000-0003-2554-6205. E-mail: bersnatasha@mail.ru \\ (C) KalmSC RAS, 2021 \\ (C) Tairov A. D., Berseneva N. A., 2021
}

\begin{abstract}
Introduction. In early nomadic societies of Central Asia, gender was the major factor in the division of labor. However, the written sources and archaeological evidence in the field do not provide enough detail to describe this division, hence the solution to the problem may be sought in the ethnographical data of the peoples, nomadic in their recent past. The article aims to analyze the household responsibilities of men and women in the nomadic societies in Central Eurasia in the $18^{\text {th }}$ - early $20^{\text {th }}$ centuries to use this data for a reconstruction of the gender labor division of the early nomadic societies in the region. Materials and methods. The study makes use of published sources on the recent nomads. Notably, the present authors proceed from the fact that, granted the largely conservative character of nomadic economy and the regional environment that remained unchanged in the period in question, the forms of regional nomadic economies were largely of a similar type. Hence, it may be possible to use the data on recently nomadic peoples for the reconstruction of the economy, culture, and socio-economic structures of the ancient nomads of the Eurasian steppes. Results. The undertaken analysis of the sources indicates a clear gender division of economic activities in the Eurasian nomadic societies in the $18^{\text {th }}-$ early $20^{\text {th }} \mathrm{cc}$. Tradition prescribed the division of household duties into strictly male and female, and any violation of the gender roles was discouraged. Conclusions. The range of economic responsibilities of men and women was clearly circumscribed in the nomadic societies of Central Eurasia, their ethnic affiliation and religion playing no part in the existent labor division structures. Men took care of the herds, keeping them safe and enlarging their
\end{abstract}


number; crafts were also largely men's field; men's duties included maintenance and protection of caravans, as well as protection of the family and aul, property and livestock from enemy raids and baranta. Women were involved in childcare and domestic chores, including processing of animal raw materials, looking after livestock in the aul, cooking food, and collecting fuel for winter seasons. Thus, the data on labor division between men and women characteristic of the recent nomads makes it possible to reconstruct the gender labor division in the societies of the early nomads in the Eurasian steppe.

Keywords: the Bashkir, the Kazakh, the Kalmyk, the Kyrgyz, the Turkmen, nomads, man, woman, household responsibilities

Acknowledgments. The reported study was funded by RFBR, project nos. 20-49-740005 'Ways of Life and Social Structure of Early Nomads in the Southern Urals, Late $7^{\text {th }}-3^{\text {rd }}$ Centuries BCE' (A. Tairov) and 20-09-00205 'Culture and Society of Early Nomads in the Southern Trans-Urals: Exploring Kichigino I Burial Site’ (N. Berseneva).

For citation: Tairov A. D., Berseneva N. A. Nomadic Communities of Central Eurasia, $18^{\text {th }}-$ Early $20^{\text {th }}$ Centuries CE: Household and Economic Responsibilities of Men and Women Revisited. Oriental Studies. 2021; 14(6): 1267-1280. (In Russ.) DOI: 10.22162/2619-0990-2021-58-6-1267-1280

\section{है}

\section{Введение}

Разделение труда в соответствии с полом издревле присуще человеку. Существовало оно и в кочевых обществах Центральной Евразии I тысячелетия до н. э. Так Геродот в сюжете о происхождении савроматов вкладывает в уста амазонок следующие слова: «...мы стреляем из лука и мечем дротики, и ездим верхом, женским же работам мы не обучены. А ваши женщины не делают ничего из того, что мы перечислили, но, оставаясь в повозках, занимаются женским трудом, не выезжая на охоту и вообще никуда» [Геродот 1992, IV: 114].

Гиппократ в сообщении о скифах отмечает, что «между скифами встречается множество евнухов; они занимаются женскими работами и говорят по-женски...» [Гиппократ 1992: 29].

Однако дошедшие до нас письменные источники этого времени не позволяют охарактеризовать хозяйственные обязанности мужчин и женщин в кочевых обществах Степной Евразии. Еще меньше возможностей предоставляет археология номадов. Решение проблемы возможно, на наш взгляд, обращением к данным этнографии по кочевым в недавнем прошлом народам Восточной Европы, Южного Урала и Центральной Азии.

Целью исследования является определение хозяйственных обязанностей мужчин и женщин в кочевых обществах Центральной
Евразии XVIII - начала XX вв. для реконструкции гендерного разделения труда в обществах ранних кочевников этого региона.

\section{Материалы и методы}

Для характеристики разделения хозяйственных обязанностей по половому признаку использованы русскоязычные источники XVIII - начала XX вв.: путевые записки, работы по истории, географии, этнографии, статистике и т. п. по кочевым народам - башкирам, казахам, калмыкам, киргизам и туркменам.

Методологической основой исследования являются принципы историзма, объективности и системности исторического процесса. Мы исходили из того, что специфика экстенсивной кочевой экономики, которая мало менялась с течением времени, и экологически сходные условия, которые приводят к выработке однотипных форм кочевого хозяйства, позволяют привлекать данные по кочевым в недавнем прошлом народам для реконструкции хозяйства, культуры, социально-экономических структур древних номадов евразийских степей, полупустынь и пустынь [Железчиков 1984: 10-12; Хазанов 1975: 23, 24; Юсупов 1987: 129; Ягодин 1971: 107].

Данный подход в исторических исследованиях не нов, так К. А. Акишев, А. Д. Таиров, В. Н. Ягодин использовали данные по казахам XVIII - начала XX вв. для реконструкции пастбищно-кочевой системы 
номадов раннего железного века урало-казахстанских степей [Акишев 1972; Таиров 1993; Ягодин 1987].

Сведения о занятиях мужчин и женщин в монгольском обществе XII-XIII вв. имеются в работе С. С. Цыпиловой, опирающейся на сообщения П. Карпини и Г. Рубрука [Цыпилова 2018: 142; Цыпилова 2019: 105].

Используя эти же сообщения, а также привлекая данные археологии и материалы по этнографии монголов, тибетцев и казахов, реконструирует положение женщин в обществе «пазырыкцев» Алтая Н. В. Полосьмак [Полосьмак 2001: 284-287].

Синтез этнографических и археологических данных позволил М. А. Очир-Горяевой обратиться к вопросу о статусе женщины в кочевом обществе [Очир-Горяева 2018]. Для реконструкции форм семьи, положения и роли женщин в социальной структуре, а также хозяйственных функций мужчины и женщины у древних тюрок В. В. Тишин, Н. Н. Сергин, И. А. Рау использовали сведения о монголах XIII в. и казахах XVIIIXIX вв. [Тишин 2012; Тишин, Серегин 2015; Pay 2012].

Краткая характеристика хозяйственных обязанностей женщины в традиционном башкирском, казахском и калмыцком обществе приведена в ряде современных исследований, посвященных правовому положению и социальному статусу женщины (см. например: [Алпысбаева и др. 2020: 375; Джунджузов 2019: 172, 175; Жапекова 2014: 82; Мусабалина 2016: 72-74; Стасевич 2011: 62; Сулейманова 2016: 71-73; Уланов, Тюмидова 2018: 174-175]. Однако специальных исследований, приводящих характеристику хозяйственных обязанностей мужчин и женщин в кочевых обществах Центральной Евразии XVIII - начала XX вв., нам найти не удалось.

Женское и мужское в хозяйстве кочевников Центральной Евразии

Изучение обширного круга русскоязычных источников XVIII - начала XX вв. по истории, географии, этнографии и статистике Центральной Евразии позволило нам дифференцировать хозяйственные обязанности в кочевых обществах этого региона по половому признаку. Причем обязанности эти не зависели от национальной принадлежности и господствующей в обществе религии. В этом нас убеждает сравнение обязанностей мужчин и женщин у казахов, киргизов, башкир и туркмен, исповедующих ислам, калмыков - приверженцев буддизма, а также крещеных калмыков.

Хозяйственные обязанности женщин в кочевых обществах Центральной Евразии XVIII - начала XX вв.

На женщине лежали, прежде всего, домашние обязанности. Она разводила огонь в очаге, приносила воду, готовила пищу и кормила семью, убирала в жилище и стирала. Она же собирала и заготавливала топливо - кизяк и хворост. Казахская пословица гласила: «Имея хорошую жену, и дрова будешь в доме иметь, а худую - то в приезд твоих родственников и товарищей найдешь дома один дым» [П 1878: 65]. Достаточно часто женщины даже седлали и расседлывали лошадей, подводили их к мужчинам [Бентковский 2011: 451, 459; Броневский 1830а: 212; Вульфсон 1901: 33; Добросмыслов 1895: 69; Зеланд 1885: 25, 28; Красовский, 1 1868: 393; Лепёхин 1772: 57; Михайлов 1900: 48; Наливкин 1913: 13; Очерки... 1859: 32; Руденко 1927: 28; Тронов 1891: $12]$.

При перекочевке женщины собирали и разбирали юрту, складывали и навьючивали на верблюдов юрту и имущество. При необходимости они могли и починить юрту [Броневский 1830а: 212; Вульфсон 1901: 33; Добросмыслов 1895: 13; Зеланд 1885: 28; Красовский, 1 1868: 393; Михайлов 1900: 48; Очерки... 1859: 32; Руденко 1927: 28].

Женщины ухаживали за скотом в ауле кормили и доили его, охраняли ночью баранов, пасли телят [Георги 1799: 100, 130; Добросмыслов 1895: 49, 105, 189, 237, 246; Зеланд 1885: 28; Красовский, 1 1868: 393; Лепёхин 1772: 55; Михайлов 1900: 48; Очерки... 1859: 32; П 1878: 22; Руденко 1927: 28; Черемшанский 1859: 148].

Они приготавливали кумыс и молочные напитки, изготавливали крупы и масло, заготавливали продукты на зиму [Бентковский 2011: 459; Букейханов 2007: 158; Георги 1799: 100; Ельницкий 1895: 108; Зеланд 1885: 28; Красовский, 1 1868: 400; Лепёхин 1772: 55; Очерки... 1859: 32; П 1878: 60; Черемшанский 1859: 148, 149].

Женщины занимались обработкой шкур и выделыванием кож, стригли овец и вычесывали пух с коз [Бентковский 2011: 451; Броневский 1830a: 232; Букейханов 2007: 
176; Военно-статистическое... 1852: 52; Георги 1799: 101; Добросмыслов 1895: 52, 57, 68, 275; Красовский, 1 1868: 400; Лепёхин 1772: 38, 39; Лепёхин 1821: 247-248; Материалы... 1915: 107; Назаров 1968: 21].

Они валяли войлок и кошмы, изготавливали веревки (арканы) [Броневский 1830а: 232; Военно-статистическое... 1852: 52; Галкин 1867: 35; Георги 1799: 101; Ельницкий 1895: 108; Зеланд 1885: 24; Красовский, 1 1868: 393; Лепёхин 1821: 247-248; Михайлов 1900: 75; Очерки... 1859: 32; Черемшанский 1859: 149].

Женщины пряли, ткали грубые шерстяные ткани, ленты и тесьму [Бентковский 2011: 451; Военно-статистическое...1852: 52; Галкин 1867: 35; Георги 1799: 101, 130; Добросмыслов 1895: 275; Зеланд 1885: 24; Красовский, 1 1868: 393; Левшин 1832: 98; Материалы... 1915: 107; Михайлов 1900: 73, 75; Руденко 1927: 20; Черемшанский 1859: 149].

Они обшивали семью, шили подушки и одеяла, мешки, торбы, дорожные и переметные сумки, потники, вязали и вышивали. Шили женщины и обувь [Бентковский 2011: 451; Военно-статистическое... 1852: 52; Гейнс 1897: 84; Добросмыслов 1895: 275-276; Зеланд 1885: 24; Левшин 1832: 92 , 98; Лепёхин 1772: 38; Лепёхин 1821: 247248; Михайлов 1900: 48, 75; Очерки... 1859: 32; Черемшанский 1859: 149].

Женщины изготавливали ковры, плели циновки, обделывали пеньку, выделывали мыло [Букейханов 2007: 174; Галкин 1867: 35; Гинс 1913: 329; Добросмыслов 1895: 56; Ельницкий 1895: 108; Зеланд 1885: 24; Красовский 1 1868: 400; Красовский, 2 1868: 143; Михайлов 1900: 48, 75; Наливкин 1913: 8; Черемшанский 1859: 149].

У казахов женщины иногда выступали в роли баксы, т. е. занимались знахарством [Ибрагимов 1872: 149; П 1878: 56]. Башкирские женщины принимали участие в заготовке сена на зиму, ремонтировали печи, затягивали окна пузырем [Черемшанский 1859: 149].

Хозяйственные обязанности мужчин в кочевых обществах Центральной Евразии XVIII - начала XX вв.

Столь же разнообразны были обязанности мужчин. Они выбирали наиболее оптимальные пути кочевания и пастбища для разных пород скота, определяли места стоянок, осуществляли выпас и охрану стад [Букейханов 2007: 194-195; Гейнс 1897: 85; Ельницкий 1895: 108; Красовский, 1 1868: 393-394; Красовский 1 1868: 22; Лепёхин 1772: 55; Михайлов 1900: 48; Очерки... 1859: 32; Юзефович 1880: 821].

Организация водопоя скота тоже лежала на мужчинах. Если не было естественных источников воды, то им приходилось рыть и чистить колодцы, изготавливать деревянные или каменные корыта для воды [Букейхан 1927: 67; Красовский, 3 1868: 22; Левшин 1832: 196; Очерки... 1859: 32; Руденко 1927: 28].

«Каждый адай имеет железную лопату, носит ее за поясом... Как в старину каждый казак обязан был иметь огниво, нож, шылбыр (веревка, которой привязывают лошадь), так каждый адай обязан за поясом иметь железную лопату - бельдеме. Ею он роет и чистит колодцы и расчищает зимою от мерзлой земли место для ночлега овец и верблюдов, колодцы и стоянки аула» [Букейхан 1927: 68].

Для зимнего содержания скота мужчины строили загоны, крытые помещения или землянки, а также производили их ремонт, подготавливали место для ночлега мелкого рогатого скота и верблюдов [Букейхан 1927: 68; Гейнс 1897: 60-61; Красовский, 1 1868: 400; Левшин 1832: 196; Очерки... 1859: 24-25, 31].

Мужчины стригли овец и верблюдов, у последних для управления они продевали палочку в носу. Мужчины производили метку и кастрацию животных, осуществляли их забой и разделку [Бухейханов 2007: 173; Вульфсон 1901: 26; Добросмыслов 1895: 48-49, 52, 98, 100, 241, 243, 247-248; Зеланд 1885: 24; Красовский 1 1868: 400].

Мужчины объезжали лошадей, обрезали их гривы и хвосты, иногда доили их [Добросмыслов 1895: 110-111; Зеланд 1885: 24; Красовский, 1 1868: 394].

При наличии оседлости они обрабатывали землю, заготавливали сено [Ельницкий 1895: 108; Красовский, 1 1868: 400; Лепёхин 1821: 247; Материалы... 1915: 100; Руденко 1927: 28].

Мужчины были кузнецами, медниками, оружейниками, плотниками и столярами, сапожниками и ювелирами, занимались соляным промыслом. Они изготавливали деревянную посуду и детали юрты, были 
тележниками и колесниками. Мужским занятием являлась резьба по дереву, кости и камню. У туркмен мужчины также занимались гончарным и мыловаренным ремеслом [Батыров 2014: 34-35; Букейханов 2007: 85-87; Гейнс 1866: 112, 123; Гейнс 1897: 98, 162; Георги 1799: 128; Иванов 1891: 29; Красовский, 1 1868: 394, 396; Материалы... 1903: 143; Михайлов 1900: 75; Назаров 1968: 22; Шнейдер 1927: 136, 143-144].

Мужчины были шорниками, изготавливали и ремонтировали сбрую, делали седла и плети. Иногда мужчины, чаще малоимущие, занимались выделкой кож, шили кожаные одежды и мешки, валяли войлок [Букейханов 2007: 86; Гейнс 1897: 98; Иванов 1891: 29; Красовский, 1 1868: 194, 396; Михайлов 1900: 75].

Мужчины заготавливали дрова, помогали женщинам изготавливать, но не собирать, кизяк [Букейханов 2007: 169; Джунджузов 2019: 175; Добросмыслов 1895: 69; Ельницкий 1895: 108; Руденко 1927: 28; Шмидт 1894: 114].

«Он помогает заготавливать кизяк, но у кочевников вы никогда не увидите мужчину, собирающего скотский помет для топлива» [Руденко 1927: 28].

Покупка необходимых в хозяйстве изделий, а также продуктов и продажа их излишков на базарах осуществлялась мужчинами [Джунджузов 2019: 175; Ельницкий 1895: 108; Зеланд 1885: 28; Шкапский 1896: 11].

Мужчины занимались сопровождением, обслуживанием и охраной торговых караванов [Завалишин 1867: 55-56; Очерки... 1859: 19-24].

Чисто мужским занятием была охота [Георги 1799: 100, 128; Джунджузов: 2019: 175; Красовский, 1 1868: 400; Михайлов 1900: 48; Назаров 1968: 22; Черемшанский 1859: 148].

У казахов врачеванием занимались баксы - преимущественно мужчины [Броневский 1830a: 217, 219; Ибрагимов 1872: 149; П 1878: 56-57].

Помимо хозяйственных забот, мужчины защищали аулы, имущество и скот от набегов противника и баранты (барымты) или сами участвовали в набегах или баранте [Броневский 1830б: 81-85; Вамбери 1868: 77; Георги 1799: 129; Казанцев 1867: 38-44; Куропаткин 1879: 32-33; Назаров 1968: 20,
26; Наливкин 1913: 14; Очерки... 1859: $34-$ 36; Шмидт 1894: 116-117].

Анализируя хозяйственные обязанности мужчин необходимо иметь в виду, что большинство имеющихся источников относятся к концу XVIII-XIX вв., т. е. ко времени, когда территории Центральной Евразии достаточно прочно вошли в состав Российского государства и в степи прекратились набеги, междоусобицы, а барымта (баранта) преследовалась и была сильно ограничена. Как отмечает источник в Семиречье, «... за более, чем 50 лет русского владычества положение совершенно изменилось. Вооруженные грабежи, наезды и войны постепенно отошли в прошлое...» [Материалы по киргизскому... 1915: 31].

«Степные междоусобия между отдельными родами прекратились и, можно думать, никогда не возобновятся, потому что правительство наше очень удачно налегло на уничтожение корня всех беспорядков баранты, допускавшейся всеми прежними законоположениями киргиз», - отмечал Н. И. Красовский [Красовский, 3 1868: 10; см. также: Завалишин 1867: 110-111; Даулбаев 1881: 113].

Поэтому из занятий мужчин были исключены такие обязанности, как вооруженная охрана имущества, участие в междоусобных столкновениях, набегах и барымте. Отпала необходимость и вооруженного сопровождения караванов. Кроме того, непосредственное знакомство путешественников и исследователей с бытом кочевников происходило, как правило, в теплое время года, когда круг хозяйственных забот мужчин был весьма ограничен.

Кроме того, надо учитывать, что развитие торговли и поступление в степь товаров фабричного производства в XIX - начале $\mathrm{XX}$ вв. вело к сокращению ремесленного производства у кочевников (см. например: [Батыров 2016: 35, 37]).

Bce это, на фоне ежедневных хозяйственных забот женщин, приводило к представлениям о том, что у казахов «единственным работником, ни минуты не сидящим без дела, является женщина. Мужчина же, как глава семьи, оставляет за собою только заботы о приискании мест под кочевку, разъезды по базарам, охоту и, в случае бедности, пастьбу скота. Жизнь он проводит постоянно на коне, разъезжая по степи, а 
дома сидит около костра в юрте, где все должно быть приготовлено ему женою» [Шкапский 1896: 11; см. также: Завалишин 1867: 117; Зеланд 1885: 28; Ельницкий 1895 : 105, 108; Наливкин 1913: 13].

Согласно Ф. А. Михайлову, «остальное от полевых работ время туркмен проводит праздно, развлекаясь охотой, посещением соседей и разговорами у пылающего костра в прихлебку с зеленым чаем... Насколько редко можно видеть туркмена за работой, настолько же туркменку без работы» [Михайлов 1900: 48].

О башкирах И. Г. Георги писал: «мужчины большую половину зимы перед очагом за трубкою табаку, а летом за кумызом в каляканье препровождают. Женщинам напротив того тем больше дела, а особливо в летнюю пору» [Георги 1799: 100].

Хозяйственная деятельность мужчин, не связанная с кустарным ремеслом, велась, главным образом, за пределами поселения, в отличие от женщин, деятельность которой ограничивалась домом, аулом и его ближайшей округой. Калмыцкая пословица гласит: «Хорош ли мужчина, узнаешь в степи, хороша ли женщина, узнаешь в ее доме» [Галимеева 2018: 70].

Традиция достаточно жестко закрепляла разделение хозяйственных обязанностей на мужские и женские. Выполнение не свойственных полу работ вызывало негативное отношение, осуждение и насмешки окружающих. «Бедные женщины, занимающиеся доением, много терпят от нетерпеливости или злости животных. Мужчины же стоят около, но ни один не поможет, потому что для мужчины считается величайшим стыдом принять участие в какой-нибудь женской работе», - писал А. Вамбери о казахах [Вамбери 1868: 73].

«У туркменов, как и у других инородцев, почти все домашние работы выполняются женщинами. По их убеждению, мужчине неприлично заниматься каким-либо домашним делом», отмечал К. Ельницкий [Ельницкий 1895: 127-128].

Вместе с тем «как ни тяжелы обязанности женщины по хозяйству, ни одна из них не ропщет в этом отношении на свою судьбу... жены вовсе не считают мужей своих виновными в установлении тяжелой работы, выпавшей на долю женщины. Напротив, этою работою они гордятся, считая муж- ской пол и недостойным её и, вместе с тем, вовсе неспособным к ней, и желавший бы облегчить труд своих жен достаточный киргиз, нет сомнения, подвергся бы насмешкам прежде всего от самих же женщин, потерявших бы к такому человеку всякое уважение», - отмечал Н. И. Красовский [Красовский, 1 1868: 395].

Хозяйственные обязанности мужчин и женщин, отмеченные у кочевников XVIII начала XX вв. Центральной Евразии, вряд ли кардинально отличались от таковых у древних и средневековых номадов евразийских степей. В этом нас убеждают данные о хозяйстве монголов XIII в., приводимые Плано Карпини и Гильомом де Рубруком. «Мужчины ничего вовсе не делают, за исключением стрел, а также имеют отчасти попечение о стадах; но они охотятся и упражняются в стрельбе... Жены их все делают: полушубки, платья, башмаки, сапоги и все изделия из кожи, также они правят повозки и чинят их, вьючат верблюдов и во всех своих делах очень проворны и скоры» [Карпини 1993: 32-33].

«Обязанность женщин состоит в том, чтобы править повозками, ставить на них жилища и снимать их, доить коров, делать масло и грут, приготовлять шкуры и сшивать их... Они шьют также сандалии (sotulares), башмаки и другое платье... Они делают также войлок и покрывают дома. Мужчины делают луки и стрелы, приготовляют стремена и уздечки и делают седла, строят дома и повозки, караулят лошадей и доят кобылиц, трясут самый кумыс, то есть кобылье молоко, делают мешки, в которых его сохраняют, охраняют также верблюдов и вьючат их. Овец и коз они караулят сообща и доят иногда мужчины, иногда женщины» [Рубрук 1993: 87].

\section{Выводы}

Анализ данных по башкирам, казахам, калмыкам, киргизам и туркменам XVIII начала XX вв., содержащихся в русскоязычных источниках, показал, что в кочевых обществах Центральной Евразии этого времени был четко обозначен круг хозяйственных обязанностей мужчин и женщин. Распределение обязанностей не зависело от национальной принадлежности и господствующей в обществе религии. Такое распределение было жестко закреплено традицией, и выполнение не свойственных полу работ 
вызывало негативное отношение окружающих.

На мужчине лежали обязанности, выполнение которых обеспечивало сохранение и воспроизводство стада - основного богатства кочевника. Мужскими были также ремесла, связанные с обработкой металлов, камня, дерева, кости и, частично, кожи. Мужчины занимались отхожими промыслами, в том числе сопровождением, обслуживанием и охраной караванов. Основные виды деятельности мужчин, не занятых ремесленным производством, осуществлялись вне пределов поселения, в отличие от женщин, вся деятельность которых сосредотачивалась в ауле или его самых ближайших окрестностях.

Женщины были заняты, прежде всего, воспитанием детей и домашними делами: готовили пищу, убирали жилище и стирали. Они обрабатывали разнообразное животное сырье, пряли, ткали, обшивали семью, занимались рукоделием. Женщины ухаживали за скотом в ауле, заготавливали продукты и

\section{Источники и литература}

Акишев 1972 - Акишев К. А. К проблеме происхождения номадизма в аридной зоне древнего Казахстана // Поиски и раскопки в Казахстане. Алма-Ата: Наука, 1972. С. 31-46.

Алпыспаева и др. 2020 - Алпыспаева Г. А., Жуман Г., Джумалиева Л. Т., Абдыкаримова Ш. Т. Правовое положение казахской женщины в семье и обществе в XIX - начале XX вв. глазами русских современников // Былые годы. 2020. Т. 55. Вып. 1. С. 370-381.

Батыров 2014 - Батыров В. В. Очерки истории традиционной культуры калмыков последней трети XVIII - первой половины XIX вв. (по материалам фондов Национального архива Республики Калмыкия). Элиста: КИГИ PAH, 2014. $250 \mathrm{c}$.

Батыров 2016 - Батыров В. В. Очерки истории традиционной культуры калмыков второй половины ХІХ в. Элиста: КИГИ РАН, 2016. $226 \mathrm{c}$.

Бентковский 2011 - Бентковский И. В. Женщина-калмычка Большедербетского улуса в физиологическом, религиозном и социальном отношениях // Опальные: Русские писатели открывают Кавказ. Антология: в 3-х т. Т. 2. Ставрополь: Изд-во СГУ, 2011. C. $450-468$.

Броневский $1830 \mathrm{a}-$ Броневский С. Б. Записки генерал-майора Броневского о киргиз-кай- топливо на зиму. Как отмечал В. В. Тишин, мужчина в кочевом обществе «являлся непосредственным добытчиком средств к существованию, женщина была ответственной за хранение, необходимую переработку и подготовку к использованию продуктов производства и потребления» [Тишин 2012: 98].

Помимо хозяйственных забот, мужчины обязаны были защищать семью и аул, имущество и скот от набегов противника и баранты (барымты). Они и сами, при благоприятных возможностях, участвовали в набегах или баранте.

Распределение хозяйственных обязанностей между мужчинами и женщинами, зафиксированное у кочевников XVIII - начала XX вв. Центральной Евразии, вряд ли сильно отличалось от такового у древних и средневековых номадов этого региона, что позволяет, с определенными оговорками, использовать имеющиеся данные для реконструкции гендерного разделения труда в обществах ранних кочевников евразийских степей.

саках Средней орды // Отечественные записки. № 124. 1830. С. 194-285.

Броневский $1830 б-$ Броневский С. Б. Записки генерал-майора Броневского о киргиз-кайсаках Средней орды // Отечественные записки. Ч. 43. 1830. С. 70-96.

Букейхан 1927 - Букейхан А. Н. Казаки Адаевского уезда // Казаки. Антропологические очерки. Материалы особого комитета по исследованию союзных и автономных республик. Вып. 3. Серия казакстанская. Л.: Изд. Особ. комитета Акад. наук по исследов. союзн. и авт. республик, 1927. С. 59-82.

Букейханов 2007 - Букейханов $A$. Н. Казахи: историко-этнографические труды. 2-е доп. изд. Астана: Алтын кітап, 2007. 303 с. (Библиотека казахской этнографии, т. 14).

Вамбери1868 - Вамбери А. Очерки Средней Азии. М.: Тип. А. И. Мамонтова и К을 1868. $363 \mathrm{c}$.

Военно-статистическое... 1852 - Военно-статистическое обозрение Российской Империи. Т. 17. Ч. 3: Киргизская степь Западной Сибири. Сост. Г. К. Сильвергельм. СПб.: Тип. Деп. Ген. штаба, 1852. 74 с.

Вульфсон 1901 - Вульфсон Э. С. Киргизы. М.: Изд. книж. магазина торг. дома С. Курнин и Ко, 1901.79 c.

Галимеева 2018 - Галимеева М. В. Мужчина в лингвокультуре калмыков и казахов // Вест- 
ник Калмыцкого университета. 2018. № 37 (1). C. 69-75.

Галкин 1867 - Галкин М. Н. Этнографические материалы по Средней Азии и Оренбургскому краю. СПб.: Тип. Кукол-Яснопольскаго, $1867.250 \mathrm{c}$.

Гейнс 1866 - Гейнс $A$. К. Киргизские очерки. III // Военный сборник. Т. L. 1866. С. 99-126.

Гейнс1897 - Гейнс А. К. Киргиз-Кайсаки (в Зауральской степи) // А. К. Гейнс. Собрание литературных трудов. Т. І. СПб.: Тип. М. М. Стасюлевича, 1897. С. 21-177.

Георги 1799 - Георги И. Г. Описание всех обитающих в Российском государстве народов. Их житейских обрядов, обыкновений, одежд, жилищ, упражнений, забав, вероисповедании и других достопримечательностей. Часть 2. О народах татарского племени и других не решенного еще происхождения Северных Сибирских. СПб.: иждивением книгопродавца Ивана Глазунова, 1799. $178 \mathrm{c}$.

Геродот - Геродот. История // Скифы: Хрестоматия / сост., введение, коммент. Т. М. Кузнецовой. М.: Высшая школа, 1992. С. 38-84.

Гинс 1913 - Гинс Г. К. В киргизских аулах (Очерки из поездки по Средней Азии) // Исторические вести. Т. CXXXIV. 1913. C. $285-332$.

Гиппократ - Гиппократ. О воздухе, водах и местностях // Скифы: Хрестоматия / сост., введение, коммент. Т. М. Кузнецовой. М.: Высшая школа, 1992. С. 87-91.

Даулбаев 1881 - Даулбаев Б. Рассказ о жизни киргиз Николаевского уезда Тургайской области с 1830 по 1880 год // Записки Оренбургского отдела Императорского Русского географического общества. Вып. 4. Оренбург: Тип. Б. Бреслина, 1881. С. 98-117.

Джунджузов 2019 - Джунджузов С. В. Семейный быт и хозяйственная деятельность крещеных калмыков Ставропольского калмыцкого войска в первой половине XIX века: влияние аккультурации и приверженность традициям // Вестник Оренбургского государственного педагогического университета. Электронный научный журнал. 2019. № 2 (30). С. 169-178.

Добросмыслов 1895 - Добросмыслов А. И. Скотоводство в Тургайской области. Оренбург: Тип. П. Н. Жаринова, 1895. 360 с.

Ельницкий 1895 - Ельницякий K. Инородцы Сибири и среднеазиатских владений России. Этнографические очерки. СПб.: Изд. Д. Д. Полубояринова, 1895. 135 с.
Жапекова 2014 - Жапекова Г. К. Статус женщины в традиционном казахском обществе // Вестник Казахского национального университета. Серия философия, культурология, политология. 2014. №1 (46). С. 78-86.

Железчиков 1984 - Железчиков Б. Ф. Некоторые вопросы развития скотоводческого хозяйства сарматов Южного Приуралья // Памятники кочевников Южного Урала. Уфа: Башкирский филиал АН СССР, 1984. C. 3-17.

Завалишин 1867 - Завалишин И. Описание Западной Сибири. Т. 3. Сибирско-киргизская степь. М.: Университетская тип. (Катков и $\left.\mathrm{K}^{\circ}\right), 1867.145 \mathrm{c}$.

Зеланд 1885 - Зеланд Н. Киргизы. Этнологический очерк // Записки Западно-Сибирского отделения Императорского Русского географического общества. Кн. VII. Вып. 2. Омск: Тип. Окружного Штаба, 1885. С. 1-78.

Ибрагимов 1872 - Ибрагимов И. И. Этнографические очерки киргизского народа // Русский Туркестан. Сборник, изданный по поводу Политехнической выставки. Вып. 2. М.: Университетская тип. (Катков и Ко), 1872. C. $120-152$.

Иванов 1891 - Иванов И. С. Внутренняя киргизская орда (Краткий статистический очерк). Астрахань: Тип. Губерн. правл., 1891. 103 с.

Казанцев 1867 - Казанцев И. Описание киргиз-кайсак. СПб.: Тип. Тов-ва «Общественная польза», 1867. 231 с.

Карпини 1993 - Карпини Плано. История монгалов, именуемых нами татарами // Путешествие в восточные страны Плано Карпини и Гильома де Рубрука. Алматы: Гылым, 1993. С. 20-74.

Красовский, 11868 - Красовский Н. И. Материалы для географии и статистики России, собранные офицерами Генерального штаба. Область Сибирских киргизов. Ч. 1. СПб.: Тип. Траншеля, Ретгера и Шнейдера, 1868. 472 c.

Красовский, 21868 - Красовский Н. И. Материалы для географии и статистики России, собранные офицерами Генерального штаба. Область сибирских киргизов. Часть II. СПб.: Печатано в типографии Траншеля, Ретгера и Шнейдера, 1868. 464 с.

Красовский, 31868 - Красовский Н. И. Материалы для географии и статистики России, собранные офицерами Генерального штаба. Область Сибирских киргизов. Часть 3. СПб.: Тип. Траншеля, Ретгера и Шнейдера, 1868. 282 c. 
Куропаткин 1879 - Куропаткин А. Туркмения и туркмены. СПб.: Тип. В. А. Полетики, $1879.57 \mathrm{c}$.

Левшин 1832 - Левшин А. Описание киргиз-казачьих, или киргиз-кайсакских орд и степей. Часть Третья: Этнографические известия. СПб.: Тип. Карла Крайя, 1832. 304 с.

Лепёхин 1772 - Лепёхин И. И. Продолжение Дневных записок путешествия академика и медицины доктора Ивана Лепехина по разным провинциям Российского государства в 1770 году. СПб.: Имп. акад. наук, 1772. $338 \mathrm{c}$.

Лепёхин 1821 - Лепёхин И. И. Записки путешествия академика Лепёхина // Полное собрание ученых путешествий по России. Т. 3. Ч. 1, 2. СПб.: Имп. Акад. наук, 1821. 540 с.

Материалы ... 1915 - Материалы по землепользованию кочевого киргизского населения южной части Ферганской области (Ошский, Скобелевский и Кокандский уезды). Ташкент: Тип.-лит. В. М. Ильина, 1915. 230 с.

Материалы ... 1903 - Материалы по киргизскому землепользованию, собранные и разработанные Экспедицией по исследованию степных областей. T. V. Тургайская область, Кустанайский уезд. Воронеж: Тип.-лит. В. И. Исаева, 1903. 805 с.

Материалы по киргизскому... 1915 - Материалы по киргизскому землепользованию района реки Чу и низовьев реки Таласа Черняевского и Аулиеатинского уездов Сыp-Дарьинской области. Ташкент: Тип.-лит. В. М. Ильина, 1915. 225 с.

Михайлов 1900 - Михайлов Ф. А. Туземцы Закаспийской области и их жизнь. Этнографический очерк. Асхабад: Паровая тип. К. М. Федорова, 1900. 80 с.

Мусабалина 2016 - Мусабалина Г. Женщина в традиционной казахской семье: исторический аспект // Вестник тюркского мира. 2016. № 1 (10). С. 71-75.

Назаров 1968 - Назаров Ф. Записки о некоторых народах и землях средней части Азии. М.: ГРВЛ, Наука, 1968. 77 с.

Наливкин 1913 - Наливкин В. П. Туземцы раньше и теперь. Ташкент: Электрич. типо-лит. «Турк. Тов-ва Печатного Дела», 1913. 144 с.

Очерки... 1859 - Очерки зауральской степи и Внутренней или Букеевской орды. М.: Тип. В. Грачева и комп., $1859.91 \mathrm{c}$.

Очир-Горяева 2018 - Очир-Горяева М. А. Возраст и статус женщины в кочевом обществе: этноархеологический экскурс // $\mathrm{MoH}$ головедение. 2018. № 15. С. 108-123. DOI: 10.22162/2500-1523-2018-15-108-123
П 1878 - П. Обычаи киргизов Семипалатинской области // Русский вестник. Т. 137. М., 1878, № 9, сентябрь. С. 22-66.

Полосьмак 2001 - Полосьмак Н. В. Всадники Укока. Новосибирск: ИНФОЛИО-пресс, 2001. $336 \mathrm{c}$.

Pay 2012 - Рау И. А. Женщина и мужчина в семье древних тюрков и иных кочевников // Вестник Казахского национального педагогического университета имени Абая. Серия «Социологические и политические науки». 2012. № 2 (38). С. 94-96.

Рубрук 1993 - Рубрук Гильом де. Путешествие в восточные страны Вильгельма де Рубрук в лето благости 1253 // Путешествие в восточные страны Плано Карпини и Гильома де Рубрука. Алматы: Гылым, 1993. С. 76-173.

Руденко 1927 - Руденко С. Очерк быта казаков бассейна рек Уила и Сагыза// Казаки. Антропологические очерки. Материалы особого комитета по исследованию союзных и автономных республик. Вып. 3. Серия казакстанская. Л.: Изд. Особ. комитета Акад. наук по исследованию союзных и автоном. респ., 1927. С.7-32.

Стасевич 2011 - Стасевич И. В. Социальный статус женщины у казахов: традиции и современность. СПб.: Наука, 2011. 202 с.

Сулейманова 2016 - Сулейманова Р. Н. «Положение ее довольно сносно...»: взгляды отечественных исследователей второй половины XIX - начала XX в. на положение женщин в традиционном обществе (на примере башкир) // Женщина в российском обществе. 2016. № 2 (79). С. 69-81.

Таиров 1993 - Таиров А. Д. Пастбищно-кочевая система и исторические судьбы кочевников урало-казахстанских степей в I тысячелетии до новой эры // Кочевники урало-казахстанских степей. Екатеринбург: УИФ «Наука», 1993. С. 3-23.

Тишин 2012 - Тишин В. В. К вопросу о форме семьи у древних тюрков в связи с ее хозяйственными функциями // Этнографическое обозрение. 2012. № 4. С. 92-107.

Тишин, Серегин 2015 - Тишин В. В., Серегин $H$. H. Положение женщины в древнетюркском обществе // Историческая психология и социология истории. 2015. № 1. С. 109-127.

Тронов 1891 - Тронов В. Д. Материалы по антропологии и этнологии киргиз. СПб: Паров. скоропечатня П. О. Яблонского, 1891. $42 \mathrm{c}$.

Уланов, Тюмидова 2018 - Уланов М. С., Тюмидова M. Е. Положение женщины в тра- 
диционной культуре калмыцкого этноса // Вестник Калмыцкого университета. 2018. № 39 (3). С. 172-179.

Хазанов 1975 - Хазанов А. М. Эпоха древних кочевников в евразийских степях // Ранние кочевники Средней Азии и Казахстана. Краткие тезисы докладов на конференции. Л.: Наука, 1975. С. 23-25.

Цыпилова 2018 - Цыпилова С. С. Женщина в средневековой Монголии: краткий исторический обзор // Гуманитарный вектор. 2018. T. 13. № 6. C. 141-145.

Цыпилова 2019 - Цыпилова С. С. Положение и роли монгольской женщины в семье (XIIХІІІ вв.) // Манускрипт. 2019. Т. 12. Вып. 10. C. 104-107.

Черемшанский 1859 - Черемшанский B. M. Описание Оренбургской губернии в хозяйственно-статистическом, этнографическом и промышленном отношениях. Уфа: Тип. Оренбург. губ. правл., 1859. 472 с.

Шкапский 1896 - Шкапский Ор. Положение женщины у кочевников Средней Азии // Средне-Азиатский вестник. 1896. № 6-7. C. 1-19.

Шмидт $1894-$ Шмидт Ю. Очерк киргизской степи к югу от Арало-Иртышского водораздела, в Акмолинской области. Омск: Тип. Окруж. штаба, 1894. 149 с.

\section{References}

Akishev K. A. Revisiting the origin of nomadism in arid territories of ancient Kazakhstan. In: Surveys and Excavations in Kazakhstan. AlmaAta: Nauka, 1972. Pp. 31-46. (In Russ.)

Alpyspaeva G. A., Zhuman G., Jumaliyeva L. T., Abdykarimova Sh. T. Legal status of Kazakh woman in family and society, 19th - early 20th century: Eyewitness accounts of Russian contemporaries. Bylye Gody. 2020. Vol. 55. No. 1. Pp. 370-381. (In Russ.)

Batyrov V. V. Kalmyk Traditional Culture, Mid to Late 19th Century: Historical Essays. Elista: Kalmyk Humanities Research Institute (RAS), 2016. 226 p. (In Russ.)

Batyrov V. V., 1770s-1850s: Historical Essays. Elista: Kalmyk Humanities Research Institute (RAS), 2014. 250 p. (In Russ.)

Bentkovsky I. V. Kalmyk woman of Bolshederbetsky District in physiological, religious and social perspectives. In: The Out of Favor Ones. Russian Writers to Explore the Caucasus. Anthology. In 3 vols. Vol. 2. Stavropol: Stavropol State University, 2011. Pp. 450-468. (In Russ.)

Bronevsky S. B. Major General Bronevsky's notes on Kirghiz-Kaisaks of the Middle Horde.
Шнейдер 1927 - Шнейдер Е. Р. Казакская орнаментика // Казаки. Антропологические очерки. Материалы особого комитета по исследованию союзных и автономных республик. Вып. 11. Серия Казакстанская. Л.: Изд. Особ. комитета Акад. наук по исследов. союзн. и авт. республик, 1927. С. 135-171.

Юзефович 1880 - Юзефович В. О быте киргизов Тургайской области // Русский вестник. 1880. № 4. С. 799-832.

Юсупов 1987 - Юсупов Х. Раннекочевнические племена на территории Северо-Западного Туркменистана // Взаимодействие кочевых культур и древних цивилизаций. Тезисы докладов советско-французского симпозиума по археологии Центральной Азии и соседних регионов. Алма-Ата: Наука, 1987. C. $129-130$.

Ягодин 1971 - Ягодин В. Н. К вопросу о связях Хорезма с Поволжьем и Приуральем в первой половине I тысячелетия н. э. // Археология и этнография Башкирии. T. IV. 1971. C. 103-107.

Ягодин 1987 - Ягодин В. Н. Кочевники на северо-западных границах Хорезма // Взаимодействие кочевых культур и древних цивилизаций. Тезисы докладов советско-французского симпозиума по археологии Центральной Азии и соседних регионов. Алма-Ата: Наука, 1987. С. 133-135.

Otechestvennye zapiski. 1830. No. 124. Pp. 194-285. (In Russ.)

Bronevsky S. B. Major General Bronevsky's notes on Kirghiz-Kaisaks of the Middle Horde. Otechestvennye zapiski. 1830. No. 43. Pp. 7096. (In Russ.)

Bukeikhan A. N. Qazaqs of Adai Uyezd. In: The Qazaqs. Anthropological Essays. Vol. 3. Ser. Qazaqstan'. Leningrad: Special Committee for the Research of Soviet Republics (USSR Acad. of Sc.), 1927. Pp. 59-82. (In Russ.)

Bukeikhanov A. N. The Kazakhs: Historical and Ethnographic Writings. 2nd ed., suppl. Astana: Altyn Kitap, 2007. 303 p. (In Russ.)

Carpine P. Ystoria Mongalorum quos nos Tartaros appellamus (History of the Mongols, Which We call Tartars). In: William of Rubruck and Giovanni da Pian del Carpine's Journeys to the Eastern Parts. Almaty: Gylym, 1993. Pp. 2074. (In Russ.)

Cheremshansky V. M. Orenburg Governorate in Economic, Statistical, Ethnographic, and Industrial Perspectives. Ufa: Orenburg Governorate Office, 1859. 472 p. (In Russ.)

Daulbaev B. A narrative about Kirghizes of Turgay Oblast, 1830-1880. Zapiski Orenburgskogo 
otdela Imperatorskogo Russkogo geograficheskogo obshchestva. 1881. No. 4. Pp. 98-117. (In Russ.)

Dobrosmyslov A. I. Livestock Breeding in Turgay Oblast. Orenburg: P. Zharinov, 1895. 360 p. (In Russ.)

Dzhundzhuzov S. V. Family life and economic activities of the baptized Kalmyks of the Stavropol Kalmyk army in the first half of the XIX century: influence of acculturation and adherence to traditions. Vestnik of Orenburg State Pedagogical University. Electronic Scientific Journal. 2019. No. 2 (30). Pp. 169-178. Available at: http://www.vestospu. $\mathrm{ru} / \mathrm{archive} / 2019 / \mathrm{articles} / 922$ 2019.html (accessed: July 10, 2021). (In Russ.) DOI: 10.32516/2303-9922.2019.30.9

Essays on the Trans-Ural Steppe and Inner, Or Bukey, Horde. Moscow: V. Grachev \& Co., 1859. 91 p. (In Russ.)

Galimeeva M. V. The image of the man in Kalmyk and Kazakh linguistic cultures. Bulletin of Kalmyk University. 2018. No. 37 (1). Pp. 6975. (In Russ.)

Galkin M. N. Central Asia and Orenburg Governorate: Ethnographic Materials. St. Petersburg: Kukol-Yasnopolsky, 1867. 250 p. (In Russ.)

Georgi J. G. Description of Russia's Peoples, Their Household Rites, Customs, Clothes, Dwellings, Handicrafts, Games, Faiths, and Other Peculiarities. Part Two: Tatar Peoples and Other Yet Unidentified Tribes of Northern Siberia. St. Petersburg: I. Glazunov, 1799. 178 p. (In Russ.)

Guins G. C. About Kirghiz auls: Travel sketches from Central Asia. Istoricheskie vesti. 1913. Vol. CXXXIV. Pp. 285-332. (In Russ.)

Heins A. K. Kirghiz essays. Part III. Voennyi sbornik. 1866. Vol. L. Pp. 99-126. (In Russ.)

Heins A. K. Kirghiz-Kaisaks (In steppes of the Trans-Urals). In: Heins A. K. Collected Literary Works. Vol. I. St. Petersburg: M. Stasyulevich, 1897. Pp. 21-177. (In Russ.)

Herodotus. Histories (excerpts). In: Kuznetsova T. M. (comp.) The Scythians: A Chrestomathy. Moscow: Vysshaya Shkola, 1992. Pp. 38-84. (In Russ.)

Hippocrates. On Airs, Waters, and Places. In: Kuznetsova T. M. (comp.) The Scythians: A Chrestomathy. Moscow: Vysshaya Shkola, 1992. Pp. 87-91. (In Russ.)

Ibragimov I. I. Kirghiz people: Ethnographic essays. In: Russian Turkestan. Collected papers. Moscow: Katkov \& Co., 1872. Vol. 2. Pp. 120-152. (In Russ.)
Ivanov I. S. Inner Kirghiz Horde: A Brief Statistical Essay. Astrakhan: Astrakhan Governorate Office, 1891. 103 p. (In Russ.)

Kazantsev I. A Description of Kirghiz-Kaisaks. St. Petersburg: Obshchestvennaya Polza, 1867. 231 p. (In Russ.)

Khazanov A. M. The era of early nomads in Eurasian steppes. In: Early Nomads of Central Asia and Kazakhstan. Conference abstracts. Leningrad: Nauka, 1975. Pp. 23-25. (In Russ.)

Krasovsky N. I. Geography and Statistics of Russia: Materials Collected by General Staff Officers. Land of Siberian Kirghizes. Part 1. St. Petersburg: Tranzschel, Rätger \& Schneider, 1868. 472 p. (In Russ.)

Krasovsky N. I. Geography and Statistics of Russia: Materials Collected by General Staff Officers. Land of Siberian Kirghizes. Part 2. St. Petersburg: Tranzschel, Rätger \& Schneider, 1868. 464 p. (In Russ.)

Krasovsky N. I. Geography and Statistics of Russia: Materials Collected by General Staff Officers. Land of Siberian Kirghizes. Part 3. St. Petersburg: Tranzschel, Rätger \& Schneider. 282 p. (In Russ.)

Kuropatkin A. Turkmenia and Turkmens. St. Petersburg: V. Poletika, 1879. 57 p. (In Russ.)

Land Use Practices of Kirghiz Nomads in the Southern Part of Fergana Oblast (Osh, Skobelev and Kokand Uyezds). Collected materials. Tashkent: V. Ilyin, 1915. 230 p. (In Russ.)

Land Use Practices of Kirghizes in the Chu and Lower Talas River Basins, Chernyaevsky and Aulieatinsky Uyezds of Syr Darya Oblast. Collected materials. Tashkent: V. Ilyin, 1915. 225 p. (In Russ.)

Land Use Practices of Kirghizes: Materials Collected and Compiled by the Expedition for the Research of Steppe Oblasts. Vol. V: Turgay Oblast, Kostanay Uyezd. Voronezh: V. Isaev, 1903. 805 p. (In Russ.)

Lepekhin I. I. Across Different Provinces of Russia, 1770: A Continuance of Travel Notes by Ivan Lepekhin, Academician and Medical Doctor. St. Petersburg: Imperial Academy of Sciences, 1772. 338 p. (In Russ.)

Lepekhin I. I. Travel Notes of Academician Lepekhin. Ser. 'Complete Research Travels across Russia'. Vol. 3. Parts 1, 2. St. Petersburg: Imperial Academy of Sciences, 1821. 540 p. (In Russ.)

Levshin A. Description of Kirghiz-Qazaq, Or Kirghiz-Kaisak, Hordes and Steppes. Part 3: Ethnographic Messages. St. Petersburg: K. Kray, 1832. 304 p. (In Russ.) 
Mikhailov F. A. Indigenous Peoples of Transcaspian Oblast and Their Life: An Ethnographic Essay. Ashkhabad: K. Fedorov, 1900. 80 p. (In Russ.)

Musabalina G. Woman in Kazakh traditional family: A Historical aspect. Herald of Turkic World. 2016. No. 1 (10). Pp. 71-75. (In Russ.)

Nalivkin V. P. Native Inhabitants: Past and Present. Tashkent: Turkestan Printing Partnership, 1913. 144 p. (In Russ.)

Nazarov F. Notes on Some Peoples and Lands of Soviet Central Asia. Moscow: Nauka GRVL, 1968. 77 p. (In Russ.)

Ochir-Goryaeva M. A. Age and status of the woman in nomadic society: An ethno-archaeological insight. Mongolian Studies. 2018. No. 15. Pp. 108-123. (In Russ.) DOI: 10.22162/25001523-2018-15-108-123

P. Kirghizes of Semipalatinsk Oblast: Rites reviewed. Russkiy vestnik. 1878. Vol. 137 No. 9, September. Pp. 22-66. (In Russ.)

Polosmak N. V. Horsemen of Ukok Plateau. Novosibirsk: INFOLIO-Press, 2001. 336 p. (In Russ.)

Rau I. A. Woman and man in families of ancient Turks and other nomads. Kazakh National Pedagogical University after Abai Bulletin. Series of Sociological and Political Sciences. 2012. No. 2 (38). Pp. 94-96. (In Russ.)

Rubruck W. The Journey of William of Rubruck to the Eastern Parts in the Blessed Summer of 1253. In: William of Rubruck and Giovanni da Pian del Carpine's Journeys to the Eastern Parts. Almaty: Gylym, 1993. Pp. 76-173. (In Russ.)

Rudenko S. Qazaqs of the Uil and Sagyz River Basins: An essay on everyday life. In: The Qazaqs. Anthropological Essays. Vol. 3. Ser. Qazaqstan'. Leningrad: Special Committee for the Research of Soviet Republics (USSR Acad. of Sc.), 1927. Pp. 7-32. (In Russ.)

Schmidt Yu. Kirghiz Steppe to the South of AralIrtysh Watershed, Akmola Oblast: An Essay. Omsk: Omsk District Headquarters, 1894. 149 s.

Schneider E. R. Qazaq ornamental patterns. In: The Qazaqs. Anthropological Essays. Vol. 3. Ser. Qazaqstan'. Leningrad: Special Committee for the Research of Soviet Republics (USSR Acad. of Sc.), 1927. Pp. 135-171. (In Russ.)

Shkapsky Or. Status of woman among Central Asian nomads. Sredne-Aziatskiy vestnik. 1896. No. 6-7. Pp. 1-19. (In Russ.)

Silberhelm (comp.) Military Statistical Review of the Russian Empire. Vol. 17. Part 3: Kirghiz Steppe of Western Siberia. St. Petersburg: Imperial General Staff, 1852. 74 p. (In Russ.)
Stasevich I. V. Social Status of Kazakh Woman: Traditions and Contemporaneity. St. Petersburg: Nauka, 2011. 202 p. (In Russ.)

Suleimanova R. N. 'She is reasonably well positioned...': The views of local researchers of the second half of XIX - early XX c. on the position of women in traditional society (On the example of the Bashkirs). Woman in Russian Society. 2016. No. 2 (79). Pp. 69-81. (In Russ.)

Tairov A. D. Land use system in nomadism: Historical destinies of nomads from Ural and Kazakhstan steppes, 1st Millennium BCE. In: Nomads of Ural and Kazakhstan Steppes. Yekaterinburg: Nauka, 1993. Pp. 3-23. (In Russ.)

Tishin V. V. Form of family among ancient Turks and its ties to economic functions revisited. Etnograficheskoe obozrenie. 2012. No. 4. Pp. 92-107. (In Russ.)

Tishin V. V., Seregin N. N. Woman's status in ancient Turkic society. Historical Psychology \& Sociology. 2015. No. 1. Pp. 109-127. (In Russ.)

Tronov V. D. Kirghiz Anthropology and Ethnology. Collected materials. St. Petersburg: P. Yablonsky, 1891. 42 p. (In Russ.)

Tsypilova S. S. A woman in medieval Mongolia: A brief historical survey. Humanitarian Vector. 2018. Vol. 13. No. 6. Pp. 141-145. (In Russ.)

Tsypilova S. S. Status and role of the Mongolian woman in the family (The XII-XIII centuries). Manuscript. 2019. Vol. 12. No. 10. Pp. 104107. (In Russ.)

Ulanov M. S., Tyumidova M. E. The status of the woman in the traditional culture of Kalmyk ethnos. Bulletin of Kalmyk University. 2018. No. 39 (3). Pp. 172-179. (In Russ.)

Vámbéry Á. Essays on Central Asia. Moscow: A. Mamontov \& Co., 1868. 363 p. (In Russ.)

Wulfsohn E. S. The Kirghiz. Moscow: S. Kurnin \& Co., 1901. 79 p. (In Russ.)

Yagodin V. N. Khorezm and the Volga - Urals, early to mid-1st millennium CE: Ties revisited. In: Archaeology and Ethnography of Bashkiria. 1971. Vol. IV. Pp. 103-107. (In Russ.)

Yagodin V. N. Nomads in northwestern frontiers of Khorezm. In: Interaction between Nomadic Cultures and Ancient Civilizations. Symposium abstracts. Alma-Ata: Nauka, 1987. Pp. 133135. (In Russ.)

Yelnitsky K. Non-Russian Populations of Siberia and Russian Central Asia: Ethnographic Essays. St. Petersburg: D. Poluboyarinov, 1895. 135 p. (In Russ.)

Yusupov Kh. Tribes of early nomads in Northwest Turkmenistan. In: Interaction between Nomadic 
Cultures and Ancient Civilizations. Symposium abstracts. Alma-Ata: Nauka, 1987. Pp. 129130. (In Russ.)

Yuzefovich V. Kirghizes of Turgay Oblast: Household life reviewed. Russkiy vestnik. 1880. No. 4. Pp. 799-832. (In Russ.)

Zavalishin I. A Description of Western Siberia. Vol. 3: Kirghiz Steppe of Siberia. Moscow: Katkov \& Co., 1867. 145 p. (In Russ.)

Zeland N. The Kirghiz: An ethnological essay. Zapiski Zapadno-Sibirskogo otdeleniya Imperatorskogo Russkogo geograficheskogo obshchestva. 1885. Vol. VII. No. 2. Pp. 1-78. (In Russ.)

Zhapekova G. K. The status of women in traditional Kazakh society. Al-Farabi Kazakh National University Journal of Philosophy, Culture and Political Science. 2014. No. 1 (46). Pp. 78-86. (In Russ.)

Zhelezchikov B. F. Sarmatians of the Southern CisUrals: Some issues of livestock breeding economy revisited. In: Monuments of Nomads from the Southern Urals. Ufa: USSR Academy of Sciences (Bashkiria Branch), 1984. Pp. 3-17. (In Russ.) 